\title{
Common ground and development
}

DOI:

10.1111/cdep.12269

\section{Document Version}

Accepted author manuscript

Link to publication record in Manchester Research Explorer

\section{Citation for published version (APA):}

Bohn, M., \& Köymen, B. (2018). Common ground and development. Child Development Perspectives, 12(2), 104108. https://doi.org/10.1111/cdep.12269

\section{Published in:}

Child Development Perspectives

\section{Citing this paper}

Please note that where the full-text provided on Manchester Research Explorer is the Author Accepted Manuscript or Proof version this may differ from the final Published version. If citing, it is advised that you check and use the publisher's definitive version.

\section{General rights}

Copyright and moral rights for the publications made accessible in the Research Explorer are retained by the authors and/or other copyright owners and it is a condition of accessing publications that users recognise and abide by the legal requirements associated with these rights.

\section{Takedown policy}

If you believe that this document breaches copyright please refer to the University of Manchester's Takedown Procedures [http://man.ac.uk/04Y6Bo] or contact uml.scholarlycommunications@manchester.ac.uk providing relevant details, so we can investigate your claim.

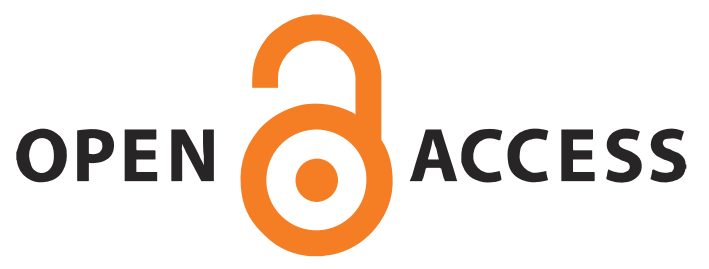


Common ground and development

Manuel Bohn ${ }^{1}$ \& Bahar Köymen ${ }^{2}$

${ }^{1}$ Stanford University

${ }^{2}$ University of Manchester

Article in press at Child Development Perspectives 


\section{Abstract}

2 Language and other forms of communication are inherently ambiguous and therefore

3 require some form of common ground to specify the intended meanings of utterances.

4 Theoretical accounts usually focus on interactions between adults and see recursive

5 mindreading to be a prerequisite of establishing common ground. In contrast to this,

6 we want to offer a developmental perspective on common ground in this review. We

7 propose that instead of using recursive mindreading, infants initially rely on the

8 expectation that communicative partners act rational in light of previous interactions.

9 This serves as a starting point for common ground to develop. Subsequently, we

10 describe the changing role of common ground across development. Initially, common

11 ground constrains the meaning of ambiguous communicative acts and facilitates

12 children's acquisition of language. Later in development, common ground makes

13 communication efficient by helping speakers to coordinate their actions and

14 intentions, and eventually to arrive at recursive mindreading. 


\section{Introduction}

16 Philosophical and psychological theories often refer to some form of "common 17 ground" as one of the constituents of human communication $(1,2)$. Due to its 18 inherently ambiguous nature, language and other forms of communication require 19 inferential reasoning from both communicative partners. The common ground shared 20 by communicative partners supposedly sets the boundaries in which these inferential 21 processes take place. Developmental theories have stressed the importance of 22 common ground for early non-verbal communication (3) as well as language 23 acquisition (4-6). Yet, what common ground is - its cognitive and motivational 24 constituents - remains rather vague in the developmental literature. More importantly, 25 it is unclear if/how the ability to form common ground develops. In this article, we 26 want to offer a theoretical account of common ground that is cognitively and 27 developmentally plausible, while conserving the idea of the inference constraining 28 effect of common ground.

Almost all accounts of common ground converge on the idea that communicators use recursive mindreading to assess which epistemic states

31 (knowledge, beliefs, etc.) are shared between communicative partners. While some 32 accounts argue that the recursive process is potentially unlimited or reflexive $(1,7)$, 33 more empirical accounts suggest that it can be limited to a few recursive steps $(6,8)$.

34 In this paper, we will follow a different approach that conceptualizes common ground 35 as a property of a social interaction rather than the consequence of individual 36 recursive mindreading (9). In this approach, common ground is something that holds 37 between two (or more) individuals who are engaged in communicative interaction. 38 While being in this situation might lead individuals to engage in recursive reasoning 39 about each other's mental states, this reasoning is not a prerequisite of their being in 
this situation. What is required to use common ground in communication is an expectation that the partner will act in line with their shared experience. Thus, communication is a "risky business" and it takes supplementary cognitive abilities to assess whether the assumption that something is part of common ground is warranted. These abilities improve during ontogeny and make children more effective and efficient communicators.

In the next section, we define a basic set of abilities and expectations that infants need to participate in communicative interactions involving ambiguous signals and to gradually develop a more sophisticated understanding of common ground. We do not attempt to cover the full scope of common ground as discussed in the philosophical literature; we seek to provide a developmentally plausible starting point.

\section{Defining Common Ground}

According to our view, common ground has a cognitive as well as a motivational component. Cognitive: Representing some $\mathrm{X}$ as shared with another individual $\mathrm{P}$. Motivational: Representing something as shared entails interacting with $\mathrm{P}$ in a way that is rational in the light of $\mathrm{X}$ and expecting $\mathrm{P}$ to act in the same way. These two components are inextricably linked because the sharedness of $\mathrm{X}$ in the cognitive part is defined by the expectations of the motivational part. This definition raises a number of questions.

\section{What is X?}

$\mathrm{X}$ is the focal topic of a social interaction, which could be, an object, a sequence of actions, a conversational theme and so on. The social aspect distinguishes common ground from the physical context because it picks out those parts that are relevant for $\mathrm{X}$ which also includes past interactions. $\mathrm{X}$ is identified by the communicative partners during episodes of spatiotemporal alignment of their attentional states within the 
broader social interaction (see e.g. 10). As we will later explicate, successful alignment improves with the development of certain socio-cognitive abilities. Early in infancy however, adults facilitate the joint encoding of a common $\mathrm{X}$ by tuning in to the infant's focus of attention.

\section{Who is $P$ ?}

Even though we usually think of $\mathrm{P}$ as a specific individual, it is not limited to that. $\mathrm{P}$ could also be conceived as a generic member of a specific social group. For example, children's early play routines might not be specific to certain individuals but open to adults in general. Most prominently, when using language, children generalize from direct interactions and expect unfamiliar others to share a certain vocabulary - unless they show signs that they speak a different language (e.g. 11). That is, the expectation that $\mathrm{X}$ is part of common ground may be rooted in the conventional use of $\mathrm{X}$ within a group.

\section{What is acting rational?}

Here we follow Grice's (12) original suggestion that communication is a form of rational action. Acting rational means producing one's communicative acts in light of $\mathrm{X}$ and expecting $\mathrm{P}$ to do the same. Acting in light of $\mathrm{X}$ in combination with the assumption that the other's acts are based on $\mathrm{X}$ ensures that common ground narrows the potential interpretations of ambiguous acts. Based on this assumption, the interpretation of the utterance is the one that follows from X. For example, in a study by Liebal and colleagues (13) children played two games, each with a different adult but involving the same toys. Later, when one of the adults ambiguously pointed to one of these toys, children resumed playing the game they played previously with that particular adult. The pointing gesture alone, even in the same physical context, could have had many other interpretations such as a request for the object, a desire to share 
interest, etc. Based on our account, children continued playing the previous game because they expected that $\mathrm{P}$ (the adult) produced this gesture in light of $\mathrm{X}$ (the previous game), because this is the rational thing to do and offers a straightforward interpretation of an otherwise ambiguous act.

Since most social interactions, especially those of young infants, are cooperative, the expectation that others communicate rationally also implies that others communicate in a cooperative/informative/relevant way. This expectation is reminiscent of Grice's cooperative principle (12) and has been highlighted as fundamental to human communication $(1,2,6,14)$.

\section{What is the basis to represent something as shared?}

On a behavioral level, the basis for representing something as shared is, at least early in development, direct social interaction. The consequence of direct social interaction is that both partners have a similar representation of the interaction and its topic so that they share this representation [the cognitive component of common ground]. This interaction creates the tendency to interact with $\mathrm{P}$ in light of $\mathrm{X}$ in the future and the expectation that $\mathrm{P}$ will do the same [the motivational component of common ground].

We argue that infants act based on this assumption but they need not represent the recursive structure of the situation (see 15 for a similar argument regarding self conscious thoughts). Early in development, this is sufficient because infants mostly communicate with adults who actively scaffold the communicative interactions by correctly interpreting the actions/intentions of the child and by making their actions/intentions transparent and easily interpretable for the child.

However, active scaffolding by adults decreases over time and is virtually absent in interactions with same-aged peers. Given a certain level of social understanding and experience with communicative interactions (normally in place 
115 around age 3), early peer interactions provide an especially rich context in which

116 children experience various failures in communication and practice fixing these

117 failures in communication because peers are less accommodating than adults. As a

118 consequence, children learn about the constitutive conditions (see below) that have to

119 hold in order for another individual to form a specific representation that matches

120 one's own. Furthermore, once linguistic abilities advance, children also learn about

121 what others experience without directly interacting with them. Taken together, this

122 requires the gradual development of an insight into others' minds and could progress

123 along the following lines: $\mathrm{P}$ must have interacted with me around $\mathrm{X}$ in the same way

124 before; P must have been present at a certain time and place; $\mathrm{P}$ must have attended to

$125 \mathrm{X}$; P must know/believe that X; P must believe that I believe that X; P must believe

126 that I believe that $\mathrm{P}$ believes that $\mathrm{X}$, and so on.

127 In traditional accounts, recursive mindreading is taken to be a necessary

128 precondition for common ground. Yet, the corresponding explicit theory of mind

129 abilities only develop around six years of age (16). Thus, our account addresses this

130 mismatch and argues that these simple set of expectations can have the inference

131 constraining effect that characterizes common ground.

\section{Common ground in development}

133 In this section, we describe the changing role of common ground in children's

134 communicative development by providing empirical evidence for early common

135 ground understanding from the literature. We present three main functions of

136 common ground: 1) It clarifies ambiguous communicative acts (gestures and early

137 words) in infancy. 2) It constrains the potential meanings of novel words and

138 facilitates language acquisition. 3) It makes communication efficient by constraining 
139 if/how something needs to be explicitly communicated and how something is referred 140 to.

\section{Ambiguous communicative acts}

142 Infants' earliest communicative interactions are naturally restricted by the limited size

143 of their communicative repertoire. The elements of this repertoire, gestures, and 144 single words, are therefore re-used for different purposes and partners have to rely on common ground to constrain their meaning in a given situation.

From 12 months onwards, infants produce and interpret ambiguous

147 communicative acts in the light of common ground. They interpret ambiguous verbal 148 requests for an object based on how they interacted with that person previously (17).

149 For example, 17-month-olds interpret an ambiguous request for "the ball" as referring 150 to the ball that they and the requester previously played with (Saylor \& Ganea, 2007; 151 see also Liebal et al., 2009). Importantly, direct social interaction around the object 152 seems to be crucial for infants to make this kind of inference and form the expectation 153 for the partner to act in line with their shared experience (19). Importantly, direct 154 interaction even leads children to overestimate their common ground with others. 155 Moll, Carpenter, and Tomasello (20) showed that 2-year-olds expected their partner to 156 know about an object when they were engaged in a conversation with the partner 157 while looking at the object, even though the partner never actually saw the object.

158 Infants also use common ground in their production $(21,22)$. For example, $12-$ 159 month-olds request absent objects by pointing to the location in which they and the 160 experimenter previously saw the object $(23,24)$. In these studies, the referential 161 connection between the location and the absent object was established during an 162 earlier interaction and children expected their partner to act based on it. 
164 In learning novel words, the child has to infer what the intended referent is. The 165 assumption that the speaker communicates based on common ground greatly limits

166 the potential referents of the novel word and thereby allows the child to complete the 167 mapping successfully. For example, if a parent and a child have been naming objects 168 based on their color and the adult introduces a novel object, the child might interpret a 169 novel word as referring to the object's color as opposed to other properties. Evidence 170 from the word learning literature supports this. At 17 months of age, children expect 171 speakers to refer to the object they previously played with, even if the speaker later 172 has a false belief about the object's location (25). From age 2 onwards, children also 173 learn words based on novelty (26), preference (27), or familiarity (28). In these 174 studies, what is novel, preferred or familiar was established during prior social 175 interaction and by expecting their partner to act rational in light of this interaction, 176 children could infer the intended referent of the novel word.

$177 \quad$ Efficient communication

178 Around age 2, children rely on various communicative strategies, such as using 179 demonstratives (e.g., "Look at that!") or repeating what they hear to build common 180 ground with their conversational partners (5). In these conversations, however, it is 181 still the caregiver that does most of the interactive work, such as tailoring the 182 conversation around the objects that children are attending to. Around ages 2-3, 183 children begin to use common ground to achieve social goals especially with their 184 same-age peers. For these interactions to be smooth/successful, children often need to 185 have a joint goal (e.g, "how do we play this game?") and coordinate their 186 actions/intentions to solve problems together. Reaching joint decisions or solving 187 problems with partners is a difficult cooperative task, as it requires accommodating 188 the needs of the conversational partners (e.g., desires, intentions, knowledge states), 
189 all of which are anchored in the common ground. Children not only monitor their

190 partners' actions, intentions, knowledge states in their interactional history, but they

191 also have specific expectations for how their partners should act like based on the 192 common ground they share.

193 From 3 years onwards, children coordinate their language and jointly agree on 194 some ad hoc conventions, or "referential pacts", with their partners. (29). Once they 195 refer to a toy as pony, children consistently refer to that referent as pony and expect 196 their conversational partners to do the same (30). This binding character of common 197 ground becomes especially apparent in pretend play in which children assign pretend 198 identities to various objects. For instance, Wyman and colleagues (31) have shown 199 that once preschoolers agree to pretend a pen to be a toothbrush, they expect their 200 play partners (and not others who do not share this common ground) to treat the pen 201 as the toothbrush and correct their partners' use of an incorrect pretend identity for the 202 pen, by using normative language ("No this has to be the toothbrush"). Children's 203 protests for violation of local conventions provides strong evidence for children's 204 partner-specific expectations that acting based on common ground is indeed the 205 "correct" and "rational" thing to do.

206 Beyond their word choices, children also appeal to common ground in their 207 more complex language such as in their explanations (32). When 3-and 5-year-old 208 peers were asked to jointly decorate a zoo, children adjusted the informativeness of 209 their justifications for their proposals depending on the common ground they share 210 with their partners to reach the correct joint decisions $(33,34)$. Similarly, Köymen and 211 colleagues (35) had preschoolers play a sorting game with a peer, who either did not 212 know the game or knew the game (as they learned about the game together) but 213 played it incorrectly. When playing with a naïve partner, 3-year-olds used normative 
214 explanations, which were more informative (e.g., "One must put the flower with the

215 flower"). However, when playing with a partner who knowingly violates the rule,

216 children relied on their common ground and used less informative statements in their

217 interventions (e.g., "No that goes here!"). Thus, preschoolers actively use and modify

218 common ground to coordinate their actions and intentions with their peer partners.

219 Importantly, in all of these studies, direct social engagement is key to establishing

220 common ground. It leads children not only to act in accordance with their common

221 ground but also to form specific expectations about how their partners should act to 222 achieve their social goals.

223 With advanced linguistic and socio-cognitive abilities, children make

224 inferences about what other people know and how they will behave based on their

225 knowledge states without directly interacting with them. Grueneisen and colleagues

226 (36) asked peer dyads to individually deposit their marbles in one of four boxes, and

227 if both children placed their marbles in the same box, they would both get a reward.

228 Crucially, each of the three boxes had the same picture while one box had a different

229 picture. 5/6-year-old children were able to correctly guess which box would be more

230 salient to their peers and which box their peers would think would be salient to them

231 without having direct interaction with one another (see also 37). Six-year-olds were

232 even successful when one child had a false belief about their peer partner's belief

233 (38). Thus, around age 6, children can engage in recursive mindreading to figure out

234 what is common ground and use this skill to successfully coordinate their actions to 235 achieve joint goals.

\section{Conclusion}

237 We argued that recursive mindreading is not a necessary prerequisite to "get common 238 ground off the ground". Children can enter the world of communication by acting 
239 rational in light of previous social interactions and expecting others to do the same.

240 Taken together with accounts about the intentional structure of human communication

$241(39,40)$, the argument put forward in this paper emphasizes the social and 242 interactional nature of human communication while making fewer demands on the 243 cognitive abilities that are involved in it, thereby offering a truly developmental 244 perspective.

245

246 
247 References:

248 1. Clark, H. (1996). Using language. Cambridge: Cambridge University Press.

2492 2. Sperber, D., \& Wilson, D. (2001). Relevance: Communication and cognition 250 (2nd ed.). Oxford ; Cambridge, MA: Blackwell Publishers.

251 3. Tomasello, M., Carpenter, M., \& Liszkowski, U. (2007). A new look at infant 252 pointing. Child Development, 78, 705-722. doi:10.1111/j.14678624.2007.01025.x

254 4. Bruner, J. (1985). Child's talk: Learning to use language. New York: W. W. $255 \quad$ Norton \& Company.

256 5. Clark, E. (2015). Common ground. In B. MacWhinney \& W. O’Grady (Eds.), 257 The Handbook of Language Emergence (pp. 328-353): John Wiley \& Sons, $258 \quad$ Inc.

259 6. Tomasello, M. (2008). Origins of human communication. Cambridge, MA: $260 \quad$ MIT Press.

261 7. Stalnaker, R. (2002). Common ground. Linguistics and philosophy, 25, 701721. doi:10.1023/A:1020867916902

263 8. Lee, B. P. H. (2001). Mutual knowledge, background knowledge and shared beliefs: Their roles in establishing common ground. Journal of Pragmatics,

2669 9ilby, M. (2010). The simplicity of mutual knowledge. Philosophical Explorations, 13, 83-100. doi:10.1080/13869791003759963

268 10. Trueswell, J. C., Lin, Y., Armstrong, B., 3rd, Cartmill, E. A., Goldin-Meadow, 269 S., \& Gleitman, L. R. (2016). Perceiving referential intent: Dynamics of reference in natural parent-child interactions. Cognition, 148, 117-135. doi:10.1016/j.cognition.2015.11.002 
272 11. Diesendruck, G. (2005). The principles of conventionality and contrast in word learning: An empirical examination. Developmental Psychology, 41, 451-463. doi:10.1037/0012-1649.41.3.451

275 12. Grice, H. P. (1989). Studies in the way of words. Cambridge, Mass.: Harvard University Press.

277 13. Liebal, K., Behne, T., Carpenter, M., \& Tomasello, M. (2009). Infants use shared experience to interpret pointing gestures. Developmental Science, 12, 264-271. doi:10.1111/j.1467-7687.2008.00758.x

280 14. Frank, M. C., \& Goodman, N. D. (2014). Inferring word meanings by assuming that speakers are informative. Cognitive Psychology, 75, 80-96. doi:10.1016/j.cogpsych.2014.08.002 25238461

15. Musholt, K. (2015). Thinking about oneself : From nonconceptual content to the concept of a self. Cambridge, Massachusetts ; London, England: MIT Press.

16. Miller, S. A. (2009). Children's understanding of second-order mental states. Psychological Bulletin, 135, 749-773. doi:10.1037/a0016854

17. Saylor, M. M., Ganea, P. A., \& Vazquez, M. D. (2011). What's mine is mine: Twelve-month-olds use possessive pronouns to identify referents. Developmental Science, 14, 859-864. doi:10.1111/j.1467-7687.2010.01034.x

18. Saylor, M. M., \& Ganea, P. (2007). Infants interpret ambiguous requests for absent objects. Developmental Psychology, 43, 696-704. doi:10.1037/00121649.43.3.696

19. Moll, H., Carpenter, M., \& Tomasello, M. (2007). Fourteen-month-olds know what others experience only in joint engagement. Developmental Science, 10, 826-835. doi:10.1111/j.1467-7687.2007.00615.x 
20. Moll, H., Carpenter, M., \& Tomasello, M. (2011). Social engagement leads 2year-olds to overestimate others' knowledge. Infancy, 16, 248-265. doi:10.1111/j.1532-7078.2010.00044.x

21. Liebal, K., Carpenter, M., \& Tomasello, M. (2010). Infants' use of shared experience in declarative pointing. Infancy, 15, 545-556. doi:10.1111/j.15327078.2009.00028.x

22. ONeill, D. K. (1996). Two-year-old children's sensitivity to a parent's knowledge state when making requests. Child Development, 67, 659-677. doi:10.1111/j.1467-8624.1996.tb01758.x

23. Bohn, M., Call, J., \& Tomasello, M. (2015). Communication about absent entities in great apes and human infants. Cognition, 145, 63-72. doi:10.1016/j.cognition.2015.08.009

24. Liszkowski, U., Schäfer, M., Carpenter, M., \& Tomasello, M. (2009). Prelinguistic infants, but not chimpanzees, communicate about absent entities. Psychological Science, 20, 654-660. doi:10.1111/j.1467-9280.2009.02346.x

25. Southgate, V., Chevallier, C., \& Csibra, G. (2010). Seventeen-month-olds appeal to false beliefs to interpret others referential communication. Developmental Science, 13, 907-912. doi:10.1111/j.1467-7687.2009.00946.x 20977561

26. Akhtar, N., Carpenter, M., \& Tomasello, M. (1996). The role of discourse novelty in early word learning. Child Development, 67, 635-645. doi:10.2307/1131837

27. Saylor, M. M., Sabbagh, M. A., Fortuna, A., \& Troseth, G. (2009). Preschoolers use speakers' preferences to learn words. Cognitive Development, 24, 125-132. doi:10.1016/j.cogdev.2008.12.003 
322

323

324

325

28. Birch, S. A. J., \& Bloom, P. (2002). Preschoolers are sensitive to the speaker's knowledge when learning proper names. Child Development, 73, 434-444. doi:10.1111/1467-8624.00416

29. Clark, H., \& Brennan, S. A. (1991). Grounding in communication. In L. B. Resnick, J. M. Levine \& S. D. Teasley (Eds.), Perspectives on socially shared cognition (pp. 127-149). Washington: APA Books.

30. Matthews, D., Lieven, E., \& Tomasello, M. (2010). What's in a manner of speaking? Children's sensitivity to partner-specific referential precedents. Developmental Psychology, 46, 749-760. doi:10.1037/a0019657 20604599

31. Wyman, E., Rakoczy, H., \& Tomasello, M. (2009). Normativity and context in young children's pretend play. Cognitive Development, 24, 146-155. doi:10.1016/j.cogdev.2009.01.003

32. Baer, C., \& Friedman, O. (2017). Fitting the message to the listener: Children selectively mention general and specific facts. Child Development. doi:10.1111/cdev.1275128181213

33. Köymen, B., Mammen, M., \& Tomasello, M. (2016). Preschoolers use common ground in their justificatory reasoning with peers. Developmental Psychology, 52, 423-429. doi:10.1037/dev0000089 26689754

34. Köymen, B., Rosenbaum, L., \& Tomasello, M. (2014). Reasoning during joint decision-making by preschool peers. Cognitive Development, 32, 74-85. doi:10.1016/j.cogdev.2014.09.001

35. Köymen, B., Schmidt, M., Rost, L., Lieven, E., \& Tomasello, M. (2015). Teaching versus enforcing game rules in preschoolers' peer interactions. Journal of Experimental Child Psychology, 135, 93-101. doi:10.1016/j.jecp.2015.02.005 25840450 
347 36. Grueneisen, S., Wyman, E., \& Tomasello, M. (2015). Children use salience to solve coordination problems. Developmental Science, 18, 495-501. doi:10.1111/desc. 12224

350 37. Goldvicht-Bacon, E., \& Diesendruck, G. (2016). Children's capacity to use cultural focal points in coordination problems. Cognition, 95-103. doi:10.1016/j.cognition.2015.12.016 26826539

353 38. Grueneisen, S., Wyman, E., \& Tomasello, M. (2015). "I know you don't know I know ... " children use second-order false-belief reasoning for peer coordination. Child Development, 86, 287-293. doi:10.1111/cdev.12264

356 39. Gomez, J. C. (1994). Mutual awareness in primate communication: A Gricean approach. In S. T. Parker, R. W. Mitchell \& M. L. Boccia (Eds.), SelfAwareness in Animals and Humans: Developmental Perspectives (1st ed., pp. 61-80). Cambridge: Cambridge University Press.

360 40. Moore, R. (2017). Gricean communication and cognitive development. The Philosophical Quarterly, 67, 303-326. doi:10.1093/pq/pqw049 